\title{
Composition of Ballast Water from Ships Arriving at Kertih Port, Malaysia with Observations on Port and Offshore Waters, and Notes on Settlement Patterns of Fouling Organisms
}

\author{
Lee Siang Hing ${ }^{1, *}$, Kesaven Bhubalan'1, Peck Ying Tan¹, and Rohaida Mat Husain ${ }^{1}$ \\ ${ }^{1}$ School of Marine and Environmental Sciences, Universiti Malaysia Terengganu, Mengabang Telipot, 21030 Kuala Terengganu, Malaysia \\ ${ }^{*}$ Corresponding author: Ishing@umt.edu.my
}

KEYWORDS

Fouling organisms Phytoplankton Ship ballast water Water quality Zooplankton

\begin{abstract}
We investigated plankton composition and water quality of ballast water from seven international ships docked at Kertih Port, Malaysia. Coscinodiscophyceae and cyanobacteria were the dominant phytoplankton found in ballast water samples, whereas copepod nauplii, Oithona sp., Microstella sp. and Paracalanus sp. were the dominant zooplankton. The densities for both phytoplankton and zooplankton in ships' ballast and port waters were higher than those of offshore samples. All water quality parameters (except $\mathrm{Cr}$ ) of port samples were within the safety levels prescribed for ports, oil and gas fields (Class 3) by the Malaysia Marine Water Quality Criteria Standard. The study of fouling organisms using PVC panels revealed that brown algae covered $87-95 \%$ of the panels' surface area but they were subsequently succeeded by barnacles, bivalves and red encrusting algae. Barnacle recruitment, however, was greatly influenced by crab predation which left behind a high percentage cover of barnacle bases as calcareous deposits on panels.
\end{abstract}

(c) The Author(s) 2018. This article is distributed under a Creative Commons Attribution-ShareAlike 4.0 International license.

\section{INTRODUCTION}

Ship's ballast water has long been recognized as a source of massive transfer of marine and freshwater organisms in coastal ecosystems (Occhipinti-Ambrogi and Savini 2003; Richardson et al. 2009; Williams et al. 1988). Depending on the species richness in a source port, a wide diversity of planktonic organisms could be transported in ballast water and discharged at the destination port when the ship's cargo load replaces the ballast (McGee et al. 2006; Lavoie et al. 1999). Marine fouling organisms such as barnacles, tunicates, and bivalves in ports and adjacent areas are often a source of recurring problems in the shipping industry. These organisms spread through ballast water as larvae or via fouling on the hulls or on other submerged surfaces of ships. Fouling organisms can colonize almost any surface of harbour infrastructure, local fishing boats, buoys and other commercial vessels berthed at the port (Lim et al. 2009; Yan et al. 2009) leading to deleterious effects such as corrosion, obstruction of flow, and increase in drag.

Kertih Port is situated on the east coast of Peninsular Malaysia, facing the South China Sea (Figure 1). In 2011, Kertih Port received approximately 790 commercial ships totalling some 24 million gross registered tonnage (GRT). About $35 \%$ of the ships arrived directly from other ports of Malaysia, 43\% from the Southeast Asian region, and the remaining percentage from other Asian countries such as China and Taiwan. As a major exporting port for liquid petro-chemical products, liquefied petroleum gas and petroleum, Kertih Port and its surrounding waters receive a variety of species originating domestically and internationally through ballast water discharge, and this increases the risk of species invasion. The number of species trans- ferred intra-coastally through domestic trading cannot be underestimated. A number of domestic ports in Malaysia also serve as international shipping hubs that receive various ballast cocktails originating from foreign ports. These domestic ports may become the gathering place for alien marine species, which in turn are transported to other ports of Malaysia.

This study aims to determine the type of plankton as well as nutrients, heavy metals and hydrocarbons in ballast water brought in from other parts of the world to Kertih Port. Plankton present at Kertih Port waters was also determined and the species composition and abundance were compared with those obtained from Terengganu offshore samples. The seasonal differences of selected pollution indicators and pathogenic bacteria namely Escherichia coli, Vibrio spp. and Enterococci at Kertih Port waters were also quantified. This study also investigated the fouling organisms' settlement pattern and bacteria attached to PVC panels immersed underwater in Kertih Port waters. Ratification of IMO International Convention for the Control and Management of Ship's Ballast Water and Sediments by the Malaysian Government on 27 September 2010 marked the willingness of the country to cooperate regionally and globally to act on marine invasive species issues. This study will provide useful information to the government to enable development of a National Ballast Water Management Strategy.

\section{MATERIALS AND METHODS}

\subsection{Ballast, port and offshore water analyses}

A total of seven samples were collected from manholes and overflow pipe of liquid bulk and liquefied petroleum gas (LPG) carrier vessels originating from Thailand, India, 


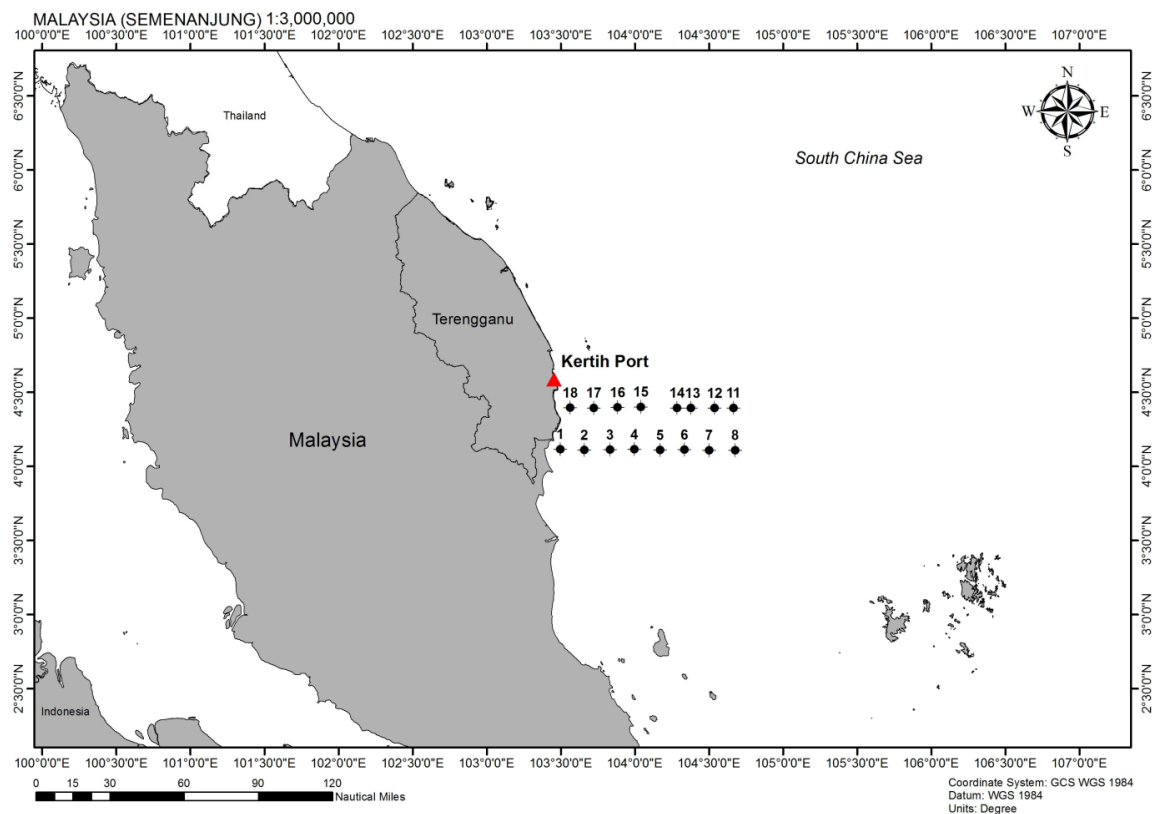

Figure 1. Location of Kertih Port along the east coast of peninsular Malaysia and water sampling stations (1-18) off the coast of Terengganu in the South China Sea.

Indonesia, and Singapore (Table 1), whereas some were a mixture from a few locations. There are no standardized ballast water sampling methods due to differences in ship construction (type of ship) and the accessibility of sampling points (David 2004). As this is a pilot study of ballast water in Malaysia, the sampling method was modified to fulfill the minimum requirement of this study without interrupting ship routine operation. The amount of water filtered for plankton studies was standardized to $100 \mathrm{~L}$. A bucket of 15-20 L capacity was used to collect water from manholes. The bucket allowed the collection of plankton at the surface.

Samples were also taken from Kertih port waters between September 2012 until May 2013 to identify local species, and to compare with samples from ballast tanks and Terengganu coastal samples from outside port waters. Terengganu coastal samples were collected over three days between 3-5 July 2013 from 18 sampling stations. Stations 1 and 18 were closest to the shore, about $10 \mathrm{~km}$ away, whereas stations 8 and 11 were the farthest, approximately $180 \mathrm{~km}$ from shore (Figure 1). Plankton samples from ballast water were collected by filtering 100 $\mathrm{L}$ of seawater through a $20 \mu \mathrm{m}$ mesh plankton net. Plankton from Kertih Port and from the 18 offshore stations were collected using a Kitahara net (mesh size $100 \mu \mathrm{m}$ ). The net was towed thrice vertically from the sea bottom

Table 1. List of vessels sampled (Ktih 1-7), vessel type and their source ports, and ballast water sampling access points. All ballast water samples were collected from 21-24 March 2011.

\begin{tabular}{llll}
\hline $\begin{array}{l}\text { Ship } \\
\text { identification }\end{array}$ & Vessel type & Source port & Access point \\
\hline Ktih 1 & Liquid bulk & Johor area (Malaysia) & Manhole \\
Ktih 2 & LPG Vessel & Kertih (Malaysia) & Manhole \\
Ktih 3 & Liquid bulk & Map Ta Phut (Thailand) & Manhole \\
Ktih 4 & Liquid bulk & Haldia (India) & Manhole (only \\
& & & 150 mL) \\
Ktih 5 & Liquid bulk & Merak (Indonesia) & Manhole \\
Ktih 6 & LPG Vessel & Singapore & Overflow Pipe \\
Ktih 7 & Liquid bulk & Mixture of water & Manhole \\
& & from Malaysia, & \\
& & Singapore and & \\
& & Indonesia & \\
& & &
\end{tabular}

or at the depth of up to $20 \mathrm{~m}$ towards the surface of the water. All samples were preserved in $10 \%$ formalin. Quantitative analyses of phytoplankton and zooplankton samples were conducted using Lackey's Drop method and Sedgewick-Rafter counting chamber, respectively (APHA, 2005). For these two methods, at least three subsamples were examined. Plankton species were classified into their respective taxonomic groups and the numbers of individuals in each group were counted. Biological diversity ( $\left.\mathrm{H}^{\prime}\right)$ and evenness (J) were calculated based on Shannon and Weaver (1963) and Pielou (1966).

For microbial analyses, water samples were filled in bottles and stored in ice chest (temperature below $4^{\circ} \mathrm{C}$ ). Microbes were cultured using selective media such as Thiosulphate Citrate Bile Salt (TCBS) agar for Vibrio spp., Enteroccocus-based agar for Enterococci spp., and m-FC agar for E. coli. The agar plates were incubated at $37^{\circ} \mathrm{C}$ for $24 \mathrm{~h}$. Physical parameters such as dissolved oxygen, salinity, temperature and $\mathrm{pH}$ were measured in situ using Hydrolab Data Sonde or Hydrolab Quanta, except for ballast water sampled via overflow pipes where only salinity was measured. Total ammonium, nitrite and orthophosphate were analyzed immediately after sampling, while total nitrogen, nitrate and total phosphorus were

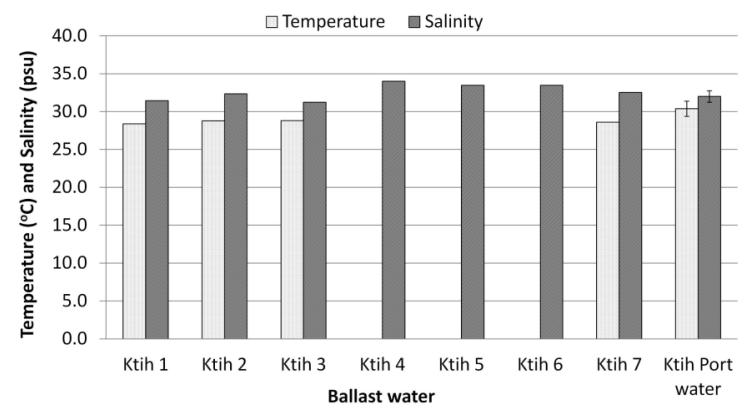

Figure 2. Temperature $\left({ }^{\circ} \mathrm{C}\right.$ ) and salinity (ppt) of ballast water and Kertih Port waters. Values for temperature and salinity shown for Kertih Port water are the monthly means from September 2012 - May 2013. Error bars represent standard deviations for the monthly data. See Table 1 for explanation of abbreviations used and port of origin of the vessels. The temperature of ballast water from Ktih 4, 5 and 6 was not measured. 


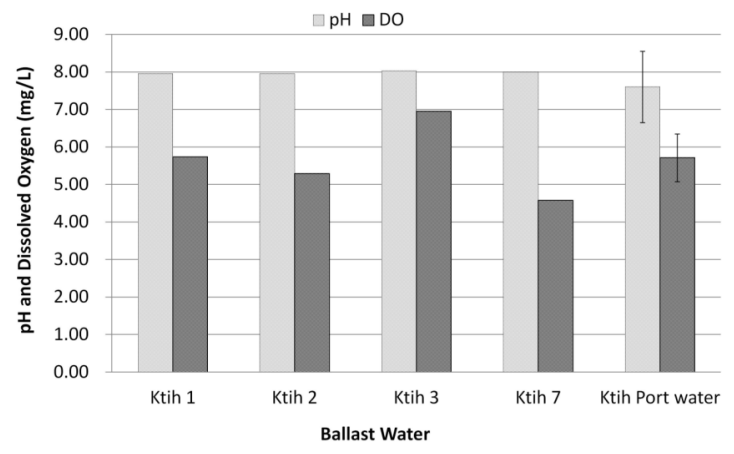

Figure 3. Variation of $\mathrm{pH}$ and dissolved oxygen (DO; mg L-1) observed in ship ballast water and of Kertih Port waters. The values for $\mathrm{pH}$ and $\mathrm{DO}$ shown for Kertih Port water were the monthly means from September 2012 - May 2013. Error bars represent standard deviations for the monthly data.Anil et al., 2003)

analyzed in the laboratory. All nutrients analyses were carried out following Parsons et al. (1984) or APHA (2005).

Heavy metal concentrations in water were analyzed following the solvent extraction method (Magnusson and Westerlund 1981; Suratman et al. 2009). The samples were extracted using ammonium pyrolidine dithiocarbamate (APDC) and methyl isobutyl ketone (MIBK), followed by determination of concentration using Inductively Coupled Plasma-Mass Spectrometry (ICP-MS) Perkin Elmer ELAN 9000. The hydrocarbons in water samples were determined following Parsons et al. (1984). The separation of Total Aliphatic hydrocarbons (TAHs) and Polycyclic Aromatic Hydrocarbon (PAHs) were done following UNEP (1992) and analyzed using Gas Chromatography/Mass Spectrometer (Shimadzu QP2010).

\subsection{Fouling studies}

Marine fouling studies were conducted using standardized PVC fouling panels $(10 \mathrm{~cm} \times 20 \mathrm{~cm})$ for 6 months at Berth 1 of Kertih Port (Figure 1). Three sets of PVC panels (3 replicates per set) were used with the first set of panels changed every month, second set changed every 3 months and the third set remained in the sea for 6 months. The panels were held submerged $1 \mathrm{~m}$ below sea surface by a floating pontoon that followed the tidal cycle. Panels were inspected and photographed every month, and the collected panels were preserved in $10 \%$ formalin for further examination. The percent cover of species present was estimated using random point analysis software (CPCe) (Kohler and Gill 2006) with fifty random points marked per plate and classified into nine groups of organisms.

\section{RESULTS}

\subsection{Ballast water from ships in Kertih Port}

Physical parameters from ballast water were measured in the present study and shown in Figures 2 and 3 . The highest salinity was recorded in ballast water from India (Ktih 4) at $34.0 \mathrm{psu}$, followed by Indonesia (Ktih 5) at 33.5 psu. Ballast water temperatures were within the range of $28.3-28.8^{\circ} \mathrm{C}$. Most ballast water samples contained high levels of dissolved oxygen with the lowest recorded as $4.57 \mathrm{mg} \mathrm{L} \mathrm{L}^{-1}$ from a mixture of water from Malaysia, Singapore and Indonesia. The $\mathrm{pH}$ values of ballast water were in the range of 7.95-8.03.

The concentrations of phosphorus and nitrogen at ship's ballast are shown in Table 2. Ship Ktih 3 (Map Ta Phut, Thailand) showed the highest concentration for total nitrogen at $2.98 \mathrm{mg} \mathrm{L}^{-1}$. The highest inorganic nitrogen concentration of $0.55 \mathrm{mg} \mathrm{L}^{-1}$ was recorded from ship Ktih 1, whereas other ships had an average value of

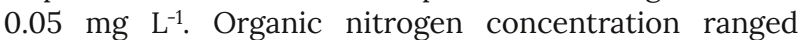
between $1.50 \mathrm{mg} \mathrm{L}^{-1}$ (Ktih 1) and $2.85 \mathrm{mg} \mathrm{L}^{-1}$ (Ktih 3).

Table 3 show the concentration of heavy metals in ballast water samples of Kertih ships. Our results showed that ballast water originating from Merak, Indonesia (Ktih 5) had the highest concentrations of chromium $\left(88.67 \mu \mathrm{g} \mathrm{L}^{-1}\right)$, iron $\left(725 \mu \mathrm{g} \mathrm{L}^{-1}\right)$, and copper $\left(23.13 \mu \mathrm{g} \mathrm{L} \mathrm{L}^{-1}\right)$. Zinc concentration was the highest $\left(250.50 \mu \mathrm{g} \mathrm{L}^{-1}\right)$ in Ktih 1 (Johor waters), while cadmium concentration was the highest $\left(33.25 \mu \mathrm{g} \mathrm{L} \mathrm{L}^{-1}\right)$ in Ktih 6 (Singapore waters). These concentrations exceeded the ranges prescribed by Malaysia Water Quality Control Standard (MWQCS), for ports, oil and gas fields (DOE, 2016).

A total of 16 individual PAH compounds were analyzed (Table 4). Naphthalene and phenanthrene were detected in all samples, but PAH compounds such as acenaphthylene, benzo[k]fluoranthene, benzo[a]pyrene, indeno [1,2,3-cd] pyrene, dibenz $[\mathrm{a}, \mathrm{h}]$ anthracene, benzo [ghi] perylene were undetectable in all ballast water samples. All ballast water samples were dominated by naphthalene (0.005-0.034 $\left.\mu \mathrm{g} \mathrm{L}^{-1}\right)$ with the highest concentration in ballast water originating from Map Ta Phut - Thailand (Ktih 3). Ballast water from Thailand contained the highest total concentration of PAHs at $0.057 \mu \mathrm{g} \mathrm{L} \mathrm{L}^{-1}$.

Figures 4 and 5 (upper panels) depict the density of plankton in ballast water. Ship's ballast water had phytoplankton densities ranging from 1754-11310 organisms $\mathrm{L}^{-1}$

Table 2. Nitrogen and phosphorus concentrations in ballast water from ships (Ktih 1-7), Kertih port waters and Malaysia Marine Water Quality Control Standards-MWQCS (DOE, 2016). NA - Not Available

\begin{tabular}{|c|c|c|c|c|c|c|c|c|}
\hline \multirow[b]{2}{*}{ Ballast Water } & \multirow[b]{2}{*}{$\begin{array}{l}\text { Nitrite } \\
(\mathrm{mg} / \mathrm{L})\end{array}$} & \multicolumn{3}{|c|}{ Nitrogen } & \multirow[b]{2}{*}{$\begin{array}{l}\text { Total } \\
\text { Nitrogen } \\
(\mathrm{mg} / \mathrm{L})\end{array}$} & \multicolumn{3}{|c|}{ Phosphorus } \\
\hline & & $\begin{array}{l}\text { Ammonia } \\
(\mathrm{mg} / \mathrm{L})\end{array}$ & $\begin{array}{l}\text { Nitrate } \\
(\mathrm{mg} / \mathrm{L})\end{array}$ & $\begin{array}{l}\text { Organic } \\
\text { Nitrogen } \\
(\mathrm{mg} / \mathrm{L})\end{array}$ & & $\begin{array}{l}\text { Ortho- } \\
\text { phosphate } \\
(\mathrm{mg} / \mathrm{L})\end{array}$ & $\begin{array}{l}\text { Organic } \\
\text { Phosphorus } \\
(\mathrm{mg} / \mathrm{L})\end{array}$ & $\begin{array}{l}\text { Total } \\
\text { Phosphorus } \\
\text { (mg/L) }\end{array}$ \\
\hline Ktih 1 & 0.00 & 0.02 & 0.53 & 1.50 & 2.05 & 0.02 & 0.00 & 0.02 \\
\hline Ktih 2 & 0.00 & 0.02 & 0.12 & 1.90 & 2.04 & 0.01 & 0.00 & 0.01 \\
\hline Ktih 3 & 0.00 & 0.03 & 0.11 & 2.85 & 2.98 & 0.00 & 0.00 & 0.00 \\
\hline Ktih 5 & 0.00 & 0.00 & 0.14 & 1.86 & 2.00 & 0.00 & 0.01 & 0.01 \\
\hline Ktih 6 & 0.00 & 0.00 & 0.16 & 2.55 & 2.72 & 0.00 & 0.02 & 0.02 \\
\hline Ktih 7 & 0.00 & 0.00 & 0.11 & 2.15 & 2.26 & 0.00 & 0.02 & 0.02 \\
\hline Ktih Port Water & $0.00 \pm 0.000$ & $0.00 \pm 0.001$ & $0.136 \pm 0.009$ & $1.507 \pm 0.789$ & $1.644 \pm 0.797$ & $0.009 \pm 0.005$ & $0.014 \pm 0.006$ & $0.022 \pm 0.001$ \\
\hline MWQCS (Class 3) & 1.00 & 0.32 & 1.00 & NA & NA & 0.67 & NA & NA \\
\hline
\end{tabular}


Table 3. Heavy metal concentrations in ballast water and Kertih port waters. The values shown are the mean and standard deviation between three replicates. NA - Not Available.

\begin{tabular}{|c|c|c|c|c|c|c|c|c|}
\hline \multirow{2}{*}{$\begin{array}{l}\text { Ballast } \\
\text { water }\end{array}$} & \multirow[t]{2}{*}{ Source port } & \multicolumn{7}{|c|}{ Concentration $(\mu \mathrm{g} / \mathrm{L})$} \\
\hline & & $\mathrm{Cr}$ & $\mathrm{Mn}$ & $\mathrm{Fe}$ & $\mathrm{Cu}$ & $\mathrm{Zn}$ & $\mathrm{Cd}$ & $\mathrm{Pb}$ \\
\hline Ktih 1 & Johor area-Malaysia & $76.33 \pm 3.22$ & $2.40 \pm 0.09$ & $680.00 \pm 47.70$ & $9.67 \pm 2.84$ & $250.50 \pm 6.38$ & $4.53 \pm 0.61$ & $12.08 \pm 9.38$ \\
\hline Ktih 2 & Kertih-Malaysia & $85.25 \pm 2.63$ & $2.19 \pm 0.22$ & $490.83 \pm 48.88$ & $2.03 \pm 1.55$ & $50.08 \pm 19.56$ & $7.13 \pm 4.09$ & $8.11 \pm 2.58$ \\
\hline Ktih 3 & Map Ta Phut-Thailand & $81.75 \pm 1.39$ & $2.55 \pm 0.03$ & $542.50 \pm 31.22$ & $4.38 \pm 1.57$ & $57.42 \pm 3.55$ & $11.83 \pm 3.29$ & $8.47 \pm 2.30$ \\
\hline Ktih 5 & Merak-Indonesia & $88.67 \pm 3.92$ & $1.84 \pm 0.60$ & $725.00 \pm 546.36$ & $23.13 \pm 17.35$ & $77.75 \pm 13.83$ & $24.34 \pm 18.07$ & $42.63 \pm 18.01$ \\
\hline Ktih 6 & Singapore & $88.50 \pm 7.45$ & $2.66 \pm 0.23$ & $515.00 \pm 19.53$ & $2.60 \pm 0.22$ & $24.34 \pm 22.92$ & $33.25 \pm 16.00$ & $16.53 \pm 0.88$ \\
\hline Ktih 7 & $\begin{array}{l}\text { Mixed of water from } \\
\text { Malaysia, Singapore \& } \\
\text { Indonesia }\end{array}$ & $72.67 \pm 4.19$ & $2.26 \pm 0.28$ & $430.00 \pm 110.00$ & $3.44 \pm 2.65$ & $53.33 \pm 8.61$ & $16.53 \pm 12.09$ & $10.88 \pm 9.73$ \\
\hline \multicolumn{2}{|c|}{ Ktih Port water } & $77.00 \pm 10.34$ & $2.29 \pm 0.36$ & $467.29 \pm 161.47$ & $3.18 \pm 2.08$ & $38.96 \pm 7.64$ & $5.77 \pm 1.25$ & $9.16 \pm 5.51$ \\
\hline \multicolumn{2}{|c|}{$\begin{array}{l}\text { MWQCSMalaysia Water Quality Control } \\
\text { Standard (Class } 3 \text { ) }\end{array}$} & 48 & NA & NA & 10 & 100 & 10 & 50 \\
\hline \multicolumn{2}{|c|}{$\begin{array}{l}\text { Estuaries and coastal water along the } \\
\text { Straits of Malacca (Looi et al., 2013) }\end{array}$} & $0.35 \pm 0.53$ & $11.28 \pm 21.39$ & $431.59 \pm 231.49$ & $86.08 \pm 82.08$ & $38.94 \pm 83.46$ & $0.58 \pm 1.59$ & $2.37 \pm 5.26$ \\
\hline
\end{tabular}

Table 4. Hydrocarbons concentrations in ballast water sampled from ship berthed at Kertih Port and port water. ND- no compound detected.

\begin{tabular}{|c|c|c|c|c|c|c|c|}
\hline \multirow[t]{2}{*}{ Compound } & \multicolumn{7}{|c|}{ Concentration $(\mu \mathrm{g} / \mathrm{L})$} \\
\hline & Ktih 1 & Ktih 2 & Ktih 3 & Ktih 5 & Ktih 6 & Ktih 7 & $\begin{array}{r}\text { Ktih Port } \\
\text { water }\end{array}$ \\
\hline Naphthalene & 0.016 & 0.012 & 0.034 & 0.011 & 0.023 & 0.018 & 0.005 \\
\hline Acenaphthene & ND & 0.002 & 0.001 & ND & ND & ND & 0.001 \\
\hline Fluorene & ND & 0.003 & 0.004 & 0.002 & ND & 0.003 & ND \\
\hline Phenanthrene & 0.003 & 0.009 & 0.007 & 0.007 & 0.003 & 0.007 & 0.004 \\
\hline Anthracene & 0.003 & 0.008 & 0.007 & 0.007 & 0.003 & ND & ND \\
\hline Fluoranthene & ND & 0.004 & 0.002 & 0.002 & ND & 0.003 & ND \\
\hline Pyrene & ND & 0.003 & 0.002 & ND & ND & 0.002 & ND \\
\hline Benz[a]anthracene & ND & 0.001 & ND & ND & ND & ND & ND \\
\hline Chrysene & ND & 0.003 & ND & ND & ND & ND & ND \\
\hline Benzo[b]fluoranthene & ND & 0.001 & ND & ND & ND & ND & ND \\
\hline Acenaphthylene & ND & ND & ND & ND & ND & ND & ND \\
\hline Benzo[k]fluoranthene & ND & ND & ND & ND & ND & ND & ND \\
\hline Benzo[a]pyrene & ND & ND & ND & ND & ND & ND & ND \\
\hline Indeno[1,2,3-cd]pyrene & ND & ND & ND & ND & ND & ND & ND \\
\hline Dibenz $[a, h]$ anthracene & ND & ND & ND & ND & ND & ND & ND \\
\hline Benzo[ghi]perylene & ND & ND & ND & ND & ND & ND & ND \\
\hline Total & 0.023 & 0.046 & 0.057 & 0.029 & 0.028 & 0.033 & 0.0103 \\
\hline
\end{tabular}

and zooplankton between 8-29 organisms $\mathrm{L}^{-1}$. The variations in phytoplankton and zooplankton composition (expressed as percentages) for ballast water are also shown in Figures 4 and 5 (lower panels), respectively. In general, all phytoplankton samples could be classified under five major classes, namely Coscinodiscophyceae, Bacillariophyceae, Fragillariophyceae, Dinophyceae and Cyanobacteria. In this study, the phytoplankton present in ballast water were dominated by the diatoms Trichodesmium sp., Chaetoceros sp., Leptocylindrus sp., and Thalassiothrix sp. (Table 5). Most of the zooplankton in ballast water samples were arthropods (classes Maxillopoda and Malacostraca) and dominated by copepod nauplii, Oithona sp., Microstella sp., and Paracalanus sp. (Table 5).

\subsection{Kertih Port waters and offshore waters}

Physical parameters data from Kertih Port water were expressed as average of monthly data from August 2012-May 2013 (Figures 2, 3). Port waters had slightly higher temperatures with mean value of $30.4 \pm 1.0^{\circ} \mathrm{C}$. In Kertih Port waters, there was large annual variation in $\mathrm{pH}$, ranging from 5.55 in April 2013 to 8.45 in November 2012. The low pH values recorded in March and April 2013 could be due to a combination of surface runoff and discharge from the nearby Kertih River, which may be more acidic than seawater. However, a more detailed study on these pH fluctuations need to be carried out to identify possible factors leading to these acidic conditions at Kertih Port. The average $\mathrm{pH}$ values of port water during monsoon season was 8.22 which indicated that the monsoon season (October-February) could also play a role in improving the mixing of water and maintaining the buffering capacity of seawater. Port waters had average DO concentration of $5.6 \mathrm{mg} \mathrm{L}^{-1}$.

Port waters had higher concentration of total phosphorus $(0.022 \mathrm{mg} / \mathrm{L})$ compared to ship's ballast water (Table 2). The levels observed in Kertih Port were within the safety level classified under ports, oil and gas field (Class 3) of MWQCS (DOE, 2011). Heavy metals concentrations of Kertih Port waters, ballast water from Singapore, Johor and offshore Kertih waters were mostly comparable (Table 3). Their concentrations were mostly below the MWQCS except for $\mathrm{Cr}\left(77.00 \pm 10.34 \mu \mathrm{g} \mathrm{L}^{-1}\right)$. Comparing the mean heavy metal concentrations in estuaries and coastal water along the Straits of Malacca, $\mathrm{Cr}$ in Kertih Port was 220 times higher and other heavy metals such as $\mathrm{Fe}, \mathrm{Cd}$ and $\mathrm{Pb}$ were 1-9 times higher (Looi et al. 2013). For PAHs, only naphthalene and phenanthrene 
Table 5. Phytoplankton and zooplankton in ballast, port and Terengganu coastal waters.

\begin{tabular}{|c|c|c|c|c|c|c|c|c|c|c|}
\hline \multirow[t]{2}{*}{ Phylum/Class } & \multirow[t]{2}{*}{ Genus } & \multicolumn{6}{|c|}{ Ballast watersampled } & \multirow{2}{*}{$\begin{array}{c}\text { Kertih Port } \\
\text { water }\end{array}$} & \multirow{2}{*}{$\begin{array}{c}\text { Terengganu } \\
\text { nearshore } \\
\text { water }\end{array}$} & \multirow{2}{*}{$\begin{array}{c}\text { Terengganu } \\
\text { offshore } \\
\text { water }\end{array}$} \\
\hline & & 㫘. & $\begin{array}{l}\text { 岸 } \\
\text { N }\end{array}$ & $\underset{\omega}{\stackrel{\text { 圧 }}{\vec{\omega}}}$ & 㫘. & $\begin{array}{l}\text { 㫘. } \\
\text { a }\end{array}$ & 㫘 & & & \\
\hline \multicolumn{11}{|l|}{ Phytoplanktonclass } \\
\hline Coscinodiscophyceae & Hemiaulus spp. & $\mathrm{X}$ & $x$ & $x$ & $x$ & & $x$ & $x$ & $x$ & $x$ \\
\hline & Cerataulina sp. & $x$ & & & & & & $x$ & & $x$ \\
\hline & Eucampia spp. & & & & & & & $x$ & $x$ & \\
\hline & Climacodium spp. & & & & & & & & $x$ & $x$ \\
\hline & Bellerocheae sp. & & & & & & & $x$ & & \\
\hline & Helicotheca sp. & & & & & & & $x$ & & \\
\hline & Chaetoceros spp. & $\mathrm{X}$ & $X$ & $\mathrm{X}$ & $\mathrm{X}$ & $\mathrm{X}$ & $X$ & $x$ & $\mathrm{X}$ & $x$ \\
\hline & Bacteriastrum spp. & $x$ & $x$ & $x$ & $\mathrm{x}$ & $\mathrm{X}$ & $x$ & $x$ & $x$ & $x$ \\
\hline & Coscinodiscus spp. & & $x$ & $x$ & $x$ & $\mathrm{X}$ & $x$ & $x$ & $x$ & $x$ \\
\hline & Biddulphia spp. & $\mathrm{X}$ & $X$ & $x$ & $x$ & & & $x$ & $X$ & $x$ \\
\hline & Leptocylindrus sp. & $x$ & $x$ & $x$ & $x$ & $x$ & $x$ & $x$ & $\mathrm{X}$ & $x$ \\
\hline & Thalassiosira sp. & & & & & & & $x$ & $x$ & \\
\hline & Cyclotella sp. & & & & & & & $x$ & & \\
\hline & Lauderia sp. & & & & & & & $x$ & $x$ & $x$ \\
\hline & Skeletonema spp. & & & & & & & $x$ & $X$ & \\
\hline & Palmeria sp. & & & & & & & $x$ & & \\
\hline & Asteromphalus spp. & & & & & & & $x$ & $x$ & $x$ \\
\hline & Odontella sp. & & & & & & & $x$ & & \\
\hline & Triceratium sp. & & & & & & & $x$ & $x$ & \\
\hline & Lampriscus sp. & & & & & & & $x$ & & \\
\hline & Stephanopyxis sp. & & & & & & & & $x$ & $x$ \\
\hline & Ditylum spp. & & & & & & & $x$ & $\mathrm{X}$ & $x$ \\
\hline & Helicotheca sp. & & & & & & & $X$ & $X$ & \\
\hline & Corethron sp. & & & & & & & $x$ & $x$ & \\
\hline & Rhizosolenia spp. & & & & & & & $x$ & $\mathrm{X}$ & $x$ \\
\hline & Proboscia sp. & & & & & & & $x$ & & \\
\hline & Pseudosolenia sp. & & & & & & & $x$ & & \\
\hline & Guinardia spp. & & & & & & & $x$ & $x$ & \\
\hline & Fragilaria sp. & & & & & & & $x$ & & \\
\hline & Licmophora sp. & & & & & & & $x$ & & \\
\hline & Grammatophora sp. & & & & & & & $x$ & & \\
\hline Bacillariophyceae & Nitzchia spp. & $x$ & $x$ & $x$ & $\mathrm{x}$ & $\mathrm{X}$ & $x$ & $x$ & $x$ & $x$ \\
\hline & Pleurosigma spp. & $x$ & $x$ & $x$ & $x$ & & $x$ & $x$ & $x$ & \\
\hline & Navicula spp. & & $x$ & & & & & $x$ & $x$ & $x$ \\
\hline & Achnanthes sp. & & & & & & & $x$ & & \\
\hline & Cocconeis sp. & & & & & & & $x$ & $x$ & \\
\hline & Diploneis sp. & & & & & & & $x$ & & \\
\hline & Meuniera sp. & & & & & & & $x$ & & \\
\hline & Bacillaria sp. & & & & & & & $x$ & & \\
\hline & Cylindrotheca sp. & & & & & & & $x$ & & \\
\hline & Pseudo-nitzschia spp. & & & & & & & $x$ & $X$ & $X$ \\
\hline & Thalassionema sp. & $x$ & $x$ & $x$ & $x$ & $x$ & & $x$ & $x$ & $x$ \\
\hline & Thalassiothrix sp. & $x$ & $x$ & $x$ & $x$ & $x$ & $x$ & $x$ & $x$ & $x$ \\
\hline & Asterionella sp. & $x$ & $x$ & $x$ & $x$ & & & $x$ & $x$ & $x$ \\
\hline Dinophyceae & Ceratium spp. & & & & $x$ & & $x$ & $x$ & $x$ & $x$ \\
\hline & Gonyaulax sp. & & & & & & & & $X$ & $x$ \\
\hline & Peridinium spp. & & & & $x$ & & $\mathrm{x}$ & $x$ & $x$ & $x$ \\
\hline & Preperidinium sp. & & & & & & & & & $x$ \\
\hline & Dinophysis spp. & & & & & & & $x$ & & $x$ \\
\hline & Ornithocercus spp. & & & & & & & & & $x$ \\
\hline & Cladophyxis sp. & & & & & & & $x$ & & \\
\hline & Pyrophacus spp. & & & & & & & $x$ & $x$ & $x$ \\
\hline & Prorocentrum spp. & & & & & & & & $x$ & $x$ \\
\hline & Pyrocystis sp. & & & & & & & & $X$ & $x$ \\
\hline Cyanobacteria & Trichodesmium sp. & $x$ & $x$ & $x$ & $x$ & $\mathrm{X}$ & & $x$ & $x$ & $x$ \\
\hline Zooplanktonphylum/class & & & & & & & & & & \\
\hline Annelida/Polychaeta & Owenia spp. & & & & & & & & $x$ & \\
\hline & Polychaete larvae spp. & & $x$ & $x$ & $x$ & & $x$ & $x$ & & $x$ \\
\hline Arthropoda/Branchiopoda & Podon sp. & & & & & & & $x$ & & \\
\hline & Evadne sp. & & & & & & & & $x$ & \\
\hline & Pseudevadne sp. & & & & & & & & & $x$ \\
\hline & Penilia sp. & & & & & & & $x$ & & \\
\hline Arthropoda/Malacostraca & Euphausia sp. & & & & & & & $x$ & & \\
\hline & Themistro sp. & & & & & & & & & $x$ \\
\hline & Amphipodasp. & & & & & & & $x$ & & \\
\hline & juvenile amphipodsp. & & & & & & & $x$ & & \\
\hline & Sergestids (Protozoea stage) & & & & & & & & & $x$ \\
\hline & Mysidsp. & & & & & & & $x$ & $x$ & \\
\hline & Shrimp larvae & & & & & & & $x$ & & \\
\hline & Zoea & & & & & & & $x$ & & \\
\hline
\end{tabular}


Table 5. Phytoplankton and zooplankton in ballast, port and Terengganu coastal waters (continued).

\begin{tabular}{|c|c|c|c|c|c|c|c|c|c|c|}
\hline \multirow[t]{2}{*}{ Phylum/Class } & \multirow[t]{2}{*}{ Genus } & \multicolumn{6}{|c|}{ Ballast watersampled } & \multirow{2}{*}{$\begin{array}{l}\text { Kertih Port } \\
\text { water }\end{array}$} & \multirow{2}{*}{$\begin{array}{c}\text { Terengganu } \\
\text { nearshore } \\
\text { water }\end{array}$} & \multirow{2}{*}{$\begin{array}{c}\text { Terengganu } \\
\text { offshore } \\
\text { water }\end{array}$} \\
\hline & & 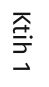 & $\begin{array}{l}\text { 蒿 } \\
\text { N }\end{array}$ & $\begin{array}{l}\text { 垁. } \\
\stackrel{5}{\omega}\end{array}$ & 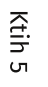 & $\begin{array}{l}\text { 蒿. } \\
\text { ă }\end{array}$ & $\begin{array}{l}\text { 奀 } \\
\text { J }\end{array}$ & & & \\
\hline \multicolumn{11}{|l|}{ Zooplanktonphylum/class } \\
\hline \multirow[t]{21}{*}{ Arthropoda/Maxillopoda } & Paracalanus spp. & & $x$ & $x$ & $x$ & & $x$ & $x$ & $x$ & $x$ \\
\hline & Acartia spp. & & & & $x$ & & & $x$ & $\mathrm{x}$ & $x$ \\
\hline & Oithona spp. & & $x$ & $x$ & & $x$ & & $x$ & $x$ & $x$ \\
\hline & Nauplius-Balanussp. & & & & & & & $x$ & & $x$ \\
\hline & Calanus sp. & & & & & & & $x$ & & \\
\hline & Canthocalanus sp. & & & & & & & $x$ & & \\
\hline & Calocalanus sp. & & & & & & & $x$ & & \\
\hline & Centropages sp. & & & & & & & $x$ & & \\
\hline & Microcalanus sp. & & & & & & & $x$ & & \\
\hline & Psedocalanus sp. & & & & & & & $x$ & & \\
\hline & Sub-eucalanus sp. & & & & & & & $x$ & & \\
\hline & Acrocalanus sp. & & & & & & & $x$ & & \\
\hline & Tortanus sp. & & & & & & & $x$ & & \\
\hline & Temora sp. & & & & & & & $x$ & $\mathrm{x}$ & $\mathrm{x}$ \\
\hline & Clytemnestra sp. & & & & & & & $x$ & & \\
\hline & Euterpina spp. & & & & & & & $x$ & $x$ & $x$ \\
\hline & Microstella spp. & $\mathrm{X}$ & $x$ & & & $x$ & $x$ & $x$ & $x$ & $x$ \\
\hline & Macrosetella sp. & & & & & & & $x$ & & \\
\hline & Corycaeus sp. & & & & & & & $x$ & & \\
\hline & Onceae sp. & & & & & & & $x$ & & \\
\hline & Sapphirina sp. & & & & & & & $x$ & & \\
\hline Arthropoda/Ostracoda & Ostracodsp. & $\mathrm{X}$ & & & $\mathrm{X}$ & & & $x$ & & \\
\hline Arthropoda/unknown & Copepod nauplii & $\mathrm{X}$ & $x$ & $\mathrm{X}$ & $x$ & $x$ & & $x$ & $x$ & $x$ \\
\hline \multirow[t]{2}{*}{ Chaetognatha/Sagittoidea } & Sagitta spp. & & & & & & & $x$ & $x$ & $x$ \\
\hline & Pterokrohnia sp. & & & & & & & $x$ & & \\
\hline \multirow[t]{2}{*}{ Chordata/Appendicularia } & Oikopleura spp. & & & & & & & $x$ & $x$ & $x$ \\
\hline & Fritillaria spp. & & & & & & & & $x$ & \\
\hline Chordata/Thaliaceae & Salpa sp. & & & & & & & $x$ & & $x$ \\
\hline Ciliophora/Spirotrichea & Order Tintinnida & $\mathrm{X}$ & $\mathrm{X}$ & & & & $x$ & & $\mathrm{X}$ & $x$ \\
\hline Cnidaria/Unknown & Cnidaria & & & & & & & & & $x$ \\
\hline Echinodermata/Unknown & Echinodermataspp. & & & & & & & & & $x$ \\
\hline Mollusca/Bivalvia & Bivalvelarvae spp. & & & & & & & $x$ & $x$ & $x$ \\
\hline Mollusca/Gastropoda & Gastropoda larvae & & & & & & & $x$ & & $x$ \\
\hline \multirow{2}{*}{ Radiozoa/Polycystina } & Hexacontium sp. & & & & & & & $x$ & & \\
\hline & Radiolariaspp. & & & & & & & $x$ & & $x$ \\
\hline Sarcomastigophora & Noctiluca sp. & & & & & & & $x$ & & $x$ \\
\hline
\end{tabular}

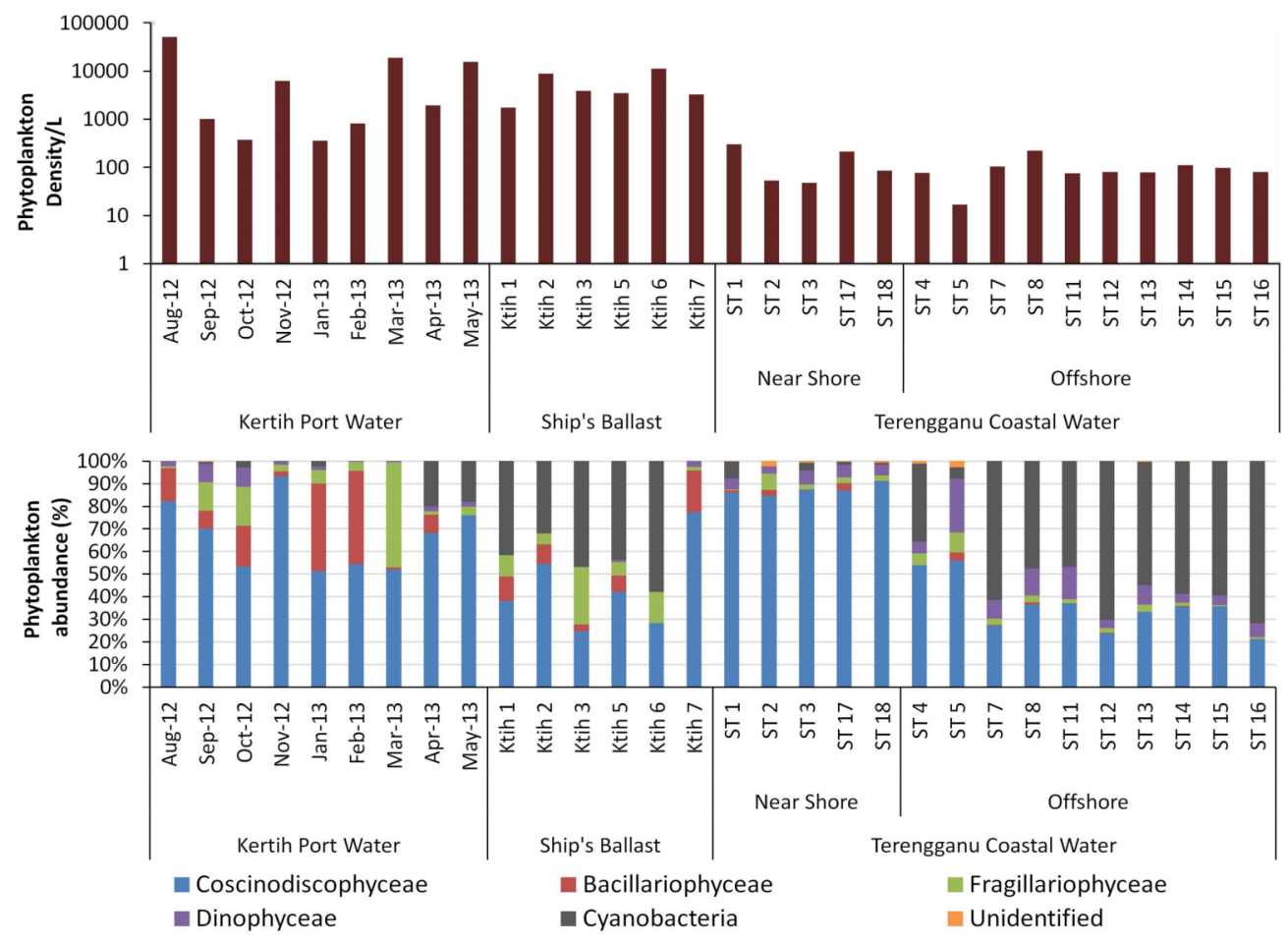

Figure 4. Density of phytoplankton (number of phytoplankton $\mathrm{L}^{-1}$ in log scale - Upper panel) and percentage abundance of major classes of phytoplankton (lower panel) in port waters, ships' ballast and Terengganu coastal (offshore) waters. 

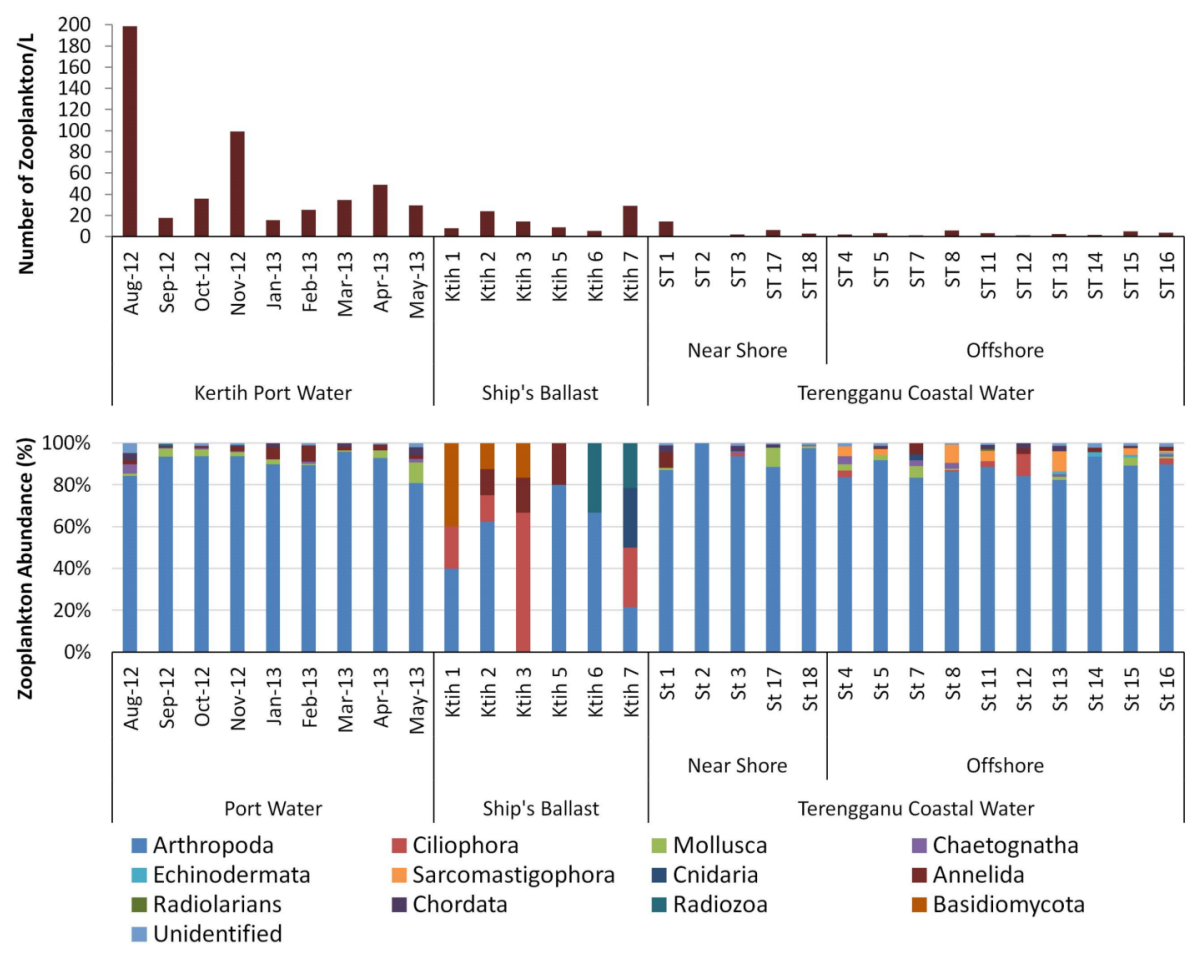

Figure 5. Density of zooplankton (number of zooplankton L-1 - Upper panel) and percentage abundance of major classes of zooplankton (lower panel) in port waters, ships' ballast water and Terengganu coastal (offshore) waters.

were present in all port water samples. Kertih Port waters had a total PAH concentration at $0.0103 \mu \mathrm{g} \mathrm{L} \mathrm{L}^{-1}$ (Table 4).

The presence of E. coli, Vibrio spp. and Enterococci in the waters of Kertih Port waters is shown in Figure 6. In general, the total indicator and pathogenic bacteria numbers were higher during the pre- and post-monsoon seasons (480-600 CFU per $100 \mathrm{~mL})$. A similar study by Ramaiah et al. (2005) in waters surrounding Mumbai Harbour showed a similar trend, whereby higher numbers of total bacteria counts were recorded during premonsoon season and the least during monsoon season. In the present study, Enterococci numbers were high throughout the sampling period, particularly during the pre- and post- monsoon seasons.

Counts of E. coli were low throughout the duration of study compared to the other bacteria types. Their highest count $(22 \pm 7 \mathrm{CFU}$ per $100 \mathrm{~mL})$ was recorded in February 2013. Enterococci counts (63-473 CFU per 100 $\mathrm{mL}$ ) were much higher than E. coli. The high numbers of

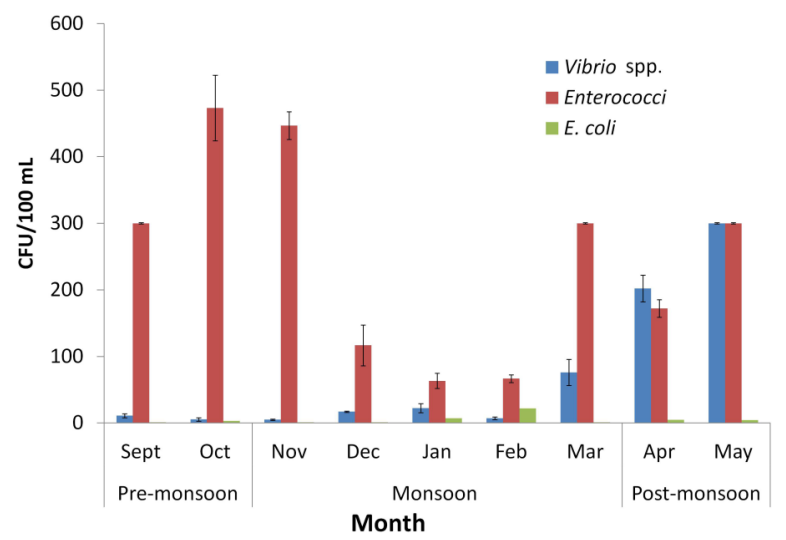

Figure 6. Enumeration of pollution indicators and pathogenic bacteria in waters at Kertih Port over the period September 2012 to May 2013.
Enterococci which exceeds the EPA's Ambient Water Quality Criteria for Bacteria - 1986 standard of $35 \mathrm{CFU}$ per $100 \mathrm{~mL}$ (U.S. EPA 1986) suggests that the area surrounding Kertih Port may not be a suitable place for recreational activities.

All phytoplankton samples obtained from Kertih Port waters and Terengganu coastal waters could be classified under five major classes namely Coscinodiscophyceae, Bacillariophyceae, Fragillariophyceae, Dinophyceae and Cyanobacteria (Figures 4 and 5). In this study, the phytoplankton present in port water and Terengganu nearshore waters were dominated by the diatoms Trichodesmium sp., Leptocylindrus sp., Chaetoceros sp., and Rhizosolenia sp. (Table 5).

In the present study, most of the zooplankton from Kertih Port waters and Terengganu coastal waters were crustaceans belonging to the classes Maxillopoda and Malacostraca and dominated by copepod nauplii, Paracalanus sp., Acartia sp., and Oithona sp. (Table 5). Both phytoplankton and zooplankton in Kertih Port waters had the highest density in August 2012 (50923 organisms $\mathrm{L}^{-1}$ and 199 organisms $\mathrm{L}^{-1}$, respectively) and the lowest density in January 2013 (361 organisms L-1 and 15 organisms $\mathrm{L}^{-1}$, respectively). Meanwhile, Terengganu coastal waters had much lower count of phytoplankton and zooplankton than Kertih Port with 17-298 and 1-14 organisms $\mathrm{L}^{-1}$, respectively.

Shannon and Weaver diversity and Pielou evenness indices of phytoplankton and zooplankton communities are shown in Figure 8. Higher values were recorded in Kertih Port waters (0.693-1.209 and 0.502-0.818, respectively) as compared to Terengganu coastal waters (0.449-0.970 and 0.392-0.745, respectively). Kertih Port water phytoplankton diversity was the highest during the inter-monsoon season (Aug-Oct 2012), and lowest during the monsoon season. Zooplankton diversity in port waters was also higher (average of 0.811) as compared to Terengganu coastal waters (0.708). 


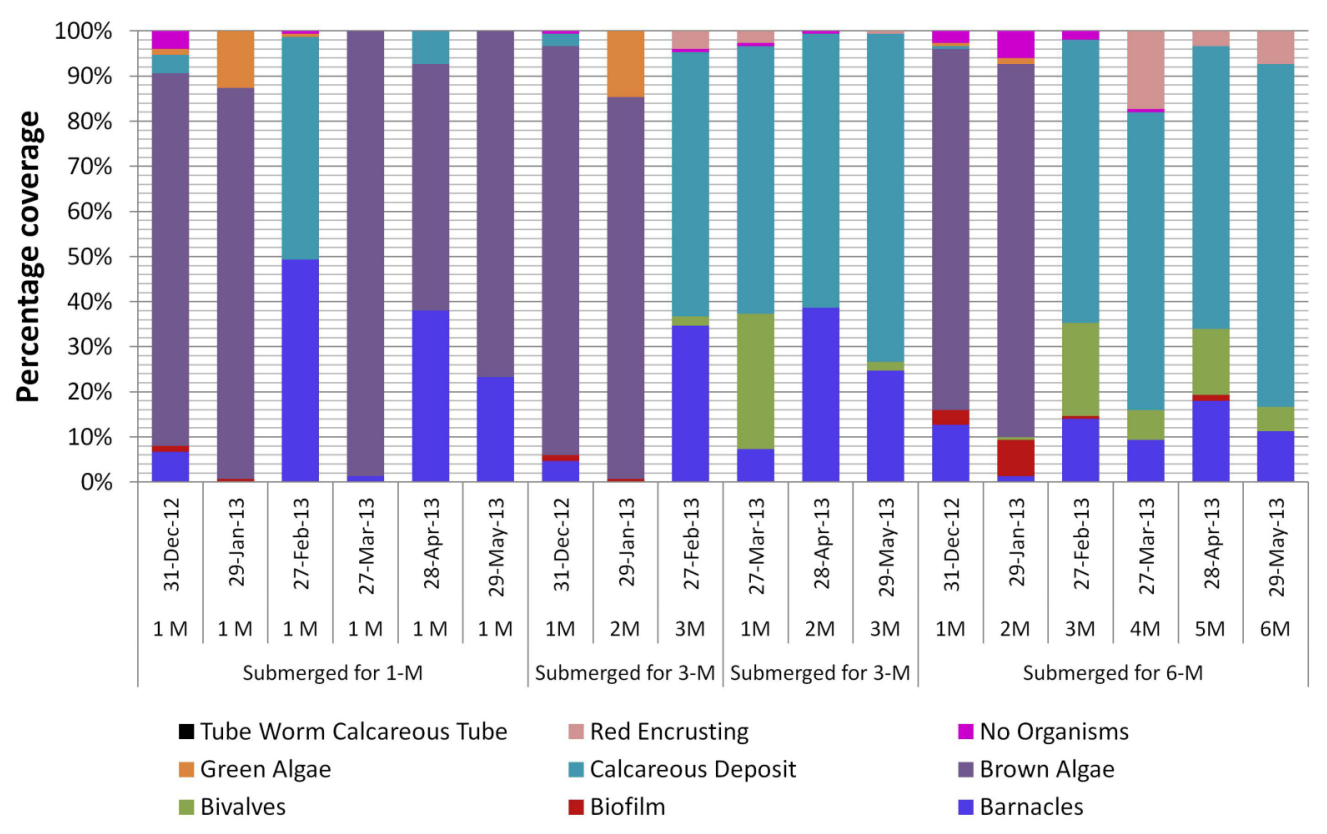

Figure 7. Fouling pattern at Kertih Port based on PVC panels immersed over 6 months (December 2012 - May 2013). There were 3 sets of panels: 1st set was immersed for one month (new panels were installed every month), $2^{\text {nd }}$ set were immersed for 3 months (new panels were installed every three months) and $3^{\text {rd }}$ set remained immersed at sea for 6 months. The percentage cover of organisms shown was the mean values of data from front and reverse sides of PVC panels. $M-$ month.

\subsection{Fouling organisms in Kertih Port}

The settlement pattern of fouling organisms at Kertih Port is shown in Figure 7. The PVC panels immersed for one month showed a similar settlement pattern over most of the year with brown algae colonizing $87-95 \%$ of the surface area, except during February and April when barnacles were the dominant organisms. High settlement rate of barnacle larvae occurred towards the end of monsoon (February onwards) and at the same time a high percentage of calcareous deposits of barnacles was also observed especially in February and April $(64.7 \%$ and $20.7 \%$, respectively) indicating high mortality of barnacles during these period. Barnacle larvae seemed to be present at a significant level in waters to initiate the settlement process once the new PVC panels were immersed on 29 January 2013 with almost $98 \%$ of the PVC panels covered by barnacles. The high settlement rate of barnacles could be due to strong water movement in the location that may be a favourable environment for feeding. Sanford et al. (1994) reported that barnacles potentially filter food at a much faster rate in swift currents. However, the recruitment of barnacles was greatly reduced due to the predation by crabs, which were abundant on the panels and panel supporting-frame structures. Predation by crabs left behind the bases of barnacles as calcareous deposits over the panel surface and reduced the live barnacle coverage to $47 \%$.

Bacteria attached onto PVC panels submerged for a period of one month at Kertih Port were also isolated and identified. Swabs containing biofilm-like bacterial slime from the PVC panels and water samples were cultured in laboratory conditions using enrichment technique in order to grow and isolate cultivable bacteria. Bacteria that were able to grow in laboratory conditions were then screened for similarity based on morphology and finally subjected to molecular identification via 16S rRNA gene cloning and DNA sequencing. The bacteria identified were Photobacterium damselae, V. parahaemolyticus, Vibrio hepatarius, and E. coli.

For the PVC panels immersed for 3 and 6 months, there was a very clear succession trend. Initially, brown al- gae covered a larger area (85-87\%) compared to other fouling organisms, and algae continued to dominate for the second month. However, by the end of the monsoon season (February), the brown algae were succeeded by barnacles (and barnacle calcareous deposits), bivalves and red encrusting algae. In particular, bivalves, once established, seemed to persist, growing slowly. At about the same time, red encrusting algae started to occupy a larger area.

\section{DISCUSSION}

The discharge of ballast water not only brought organisms but also chemical compounds such as nutrients, heavy metals and hydrocarbons. In year 2000 alone, the total amount of ballast water discharged from international trade was estimated at 2200 Mt (Endresen et al. 2004). World seaborne trade had increased steadily over the years. This implies that more ballast water, more species and more chemical pollutants will be transported from one geographical area to another.

\subsection{Chemicals in ballast water}

The impact of chemical compounds may be felt especially in an enclosed harbour where water circulation is limited and pollutants accumulate. Most of the issues reported for ballast water are related to marine species, and the transfer of chemical compounds via ballast water is somewhat neglected. The chemical compounds present in ballast water depend on the source port water quality at the time when it was taken into the ballast tank. Long term discharge and accumulation of chemical compounds in port areas will certainly impact the port ecosystem as well as its adjacent areas. Both nitrogen and phosphorus are essential for animal and plant growth. Specifically, inorganic N and P are important for phytoplankton growth (Green and Finlay 2010). Overall, nutrient concentrations in all ballast tanks were higher than in Kertih port waters. The $\mathrm{N}$ and $\mathrm{P}$ concentrations in ballast tanks were strongly dependent on the respective local conditions where the ballast water was 

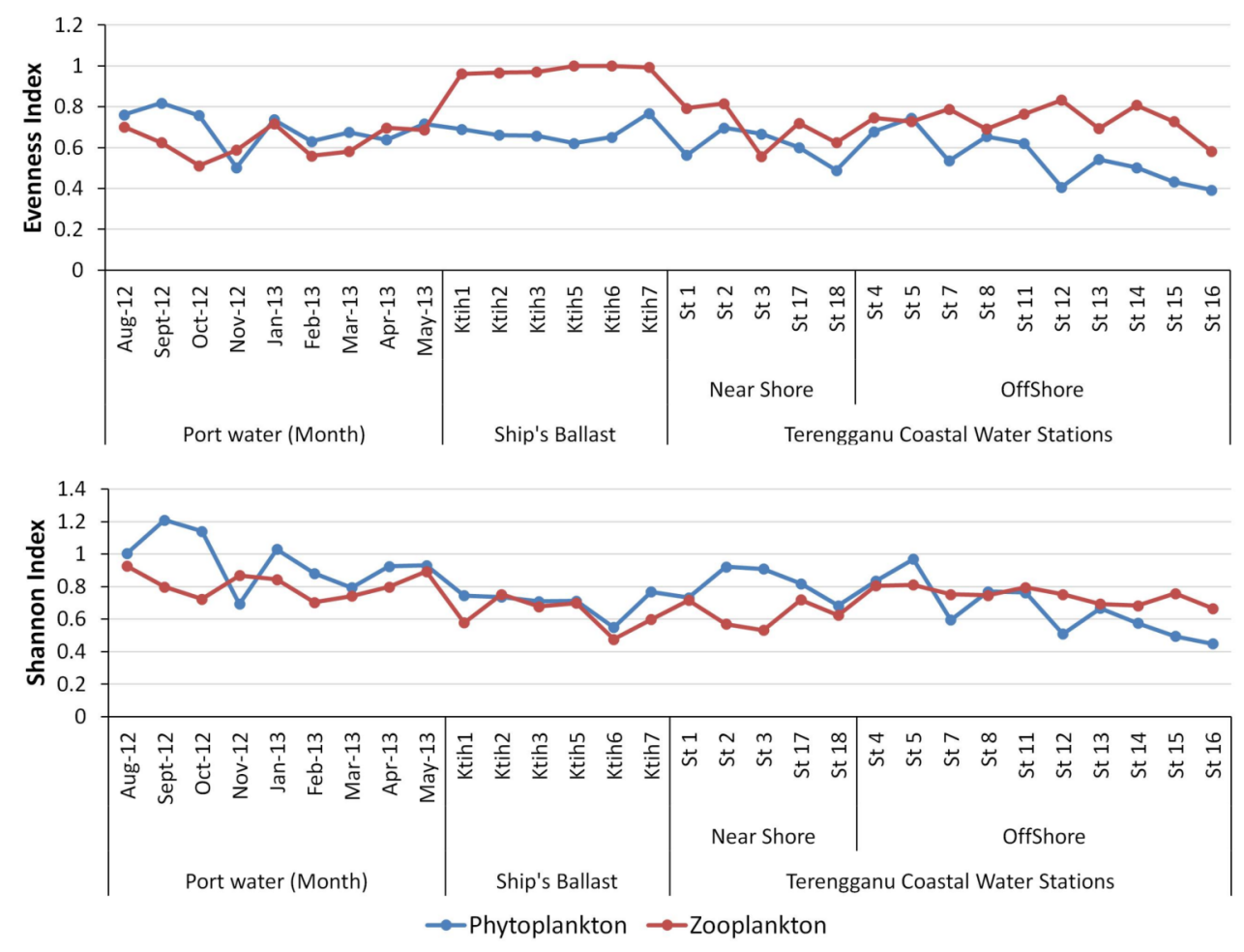

Figure 8. Variation in Shannon-Weaver diversity index and Pielou evenness index based on plankton sampled from ship ballast (Ktih1-3, 5-7), port waters over the period August 2012 to May 2013, and Terengganu coastal waters (nearshore and offshore).

taken. During the journey, the dark environment in ballast tanks promotes heterotrophic microbial uptake and thus, the nutrients' labile proportion could be mineralized within days (Roberts and Howarth 2006; Suzumura and Ingall 2004; Caron 1994). Nutrient concentrations in Kertih Port waters were much lower compared to Port Dickson in the Malacca Strait (Praveena and Aris 2012).

As a major exporting ports for petrochemical products, Kertih port constantly receives different cocktail of waters. However, most of the heavy metals and hydrocarbon concentrations in port waters did not appear increase significantly and were still within the limits set by Malaysia Water Quality Control Standard for ports, oil and gas field (Class 3). The main reason could be that Kertih Port is not an enclosed area, as the $1.4 \mathrm{~km}$ long breakwater parallel to coastline is open at both ends and does not hinder the movement of water and tidal currents, allowing free flow and continuous replenishment of adjacent water thus maintaining water quality.

\subsection{Bacteria}

Measuring the extent of pollution and presence of pathogenic bacteria, especially those that concern human health, are also essential components of port water quality studies and management. The wide physiological adaptability and detrimental effects of these bacteria necessitate a detailed understanding of their harmful effects on marine life surrounding the port environment. These bacteria might be introduced into the port waters through domestic sewage discharge, ballast movements or sewage discharged from the vessels. To date, innumerable indicator and pathogenic species might have already been transported through ballast water to ports worldwide. Nevertheless, it is important to estimate the current levels of pollution as well as pathogenic bacteria in any harbour, in order to establish baseline information useful for port water as well as ballast water management. This study found that E. coli was not detected during several samplings. High E. coli concentration in coastal waters is usually associated with land-based discharge via rivers and possibly domestic waste from ships. When coastal water is pumped into the ballast tank, E. coli will thrive by utilizing dissolved organic and inorganic substances present in ballast water. High amounts of nutrient such as nitrate and total suspended particulate matter can be observed in ballast tanks especially during rough sea conditions when ballast tank water and sediments profusely mix (Desai et al. 2017). However, low E. coli count in the port water could be due to the dilution of discharged ballast water with local seawater combined with strong water currents in Kertih Port, which might have dispersed E. coli further offshore, thus reducing their survival rates. The presence of sunlight also played an important role as it was reported to be able to greatly inactivate $E$. coli in natural environment (Chandran and Hatha 2005). The discharge of domestic sewage surrounding the port area could have been dominated by Enterococci. The dominant bacterium in the sewage discharge can compete and rapidly outgrow other native microflora due to its metabolic dominance (Nagvenkar and Ramaiah 2009). The presence of human pathogenic bacteria has always been closely related to the presence of sewage indicator bacteria. One such pathogenic group is Vibrio, which generally consists of Vibrio cholera that causes cholera and Vibrio parahaemolyticus that causes gastroenteritis in humans. The presence of Vibrio spp. was detected throughout the study period with counts in the range of 5-300 CFU per $100 \mathrm{~mL}$. Vibro spp. are known to be present year-round and this is probably due to their close association with the plankton (Khandeparker et al. 2015).

All bacteria obtained from the PVC panels were also present in the surrounding waters. These bacteria were 
previously reported as commonly occurring in the waters of South China Sea (Wong et al. 2000). Photobacterium damselae can be found on the water surface and in fishes. Occurrence of P. damselae in fishes might be attributed to production of capsular material that plays an important role in pathogenesis (Nishiguchi and Jones 2004). Vibrio parahaemolyticus has been detected in the marine environment and known to be most abundant during the warmer seasons (Wong et al. 2000). Vibrio hepatarius is also known to occur in the marine environment in association with aquatic animals (Thompson et al. 2003). However, the pathogenicity of this species is not well known.

Biofilms formed by bacteria attached onto substrates submerged in marine environment are believed to be one of the important factors initiating biofouling activity (Kristensen et al. 2008). Most bacteria excrete a self-produced matrix of extracellular polymeric substances. This biofilm is generally composed of extracellular DNA, proteins, and polysaccharides. The biofilm might in turn attract other life forms to feed on its nutrients and initiate biofouling by forcing them to adhere onto the surface of the submerged substrates. Vibrio spp. (Yildiz and Visick 2009) and E. coli (Beloin et al. 2008) produce biofilms. The presence of these bacteria on the submerged PVC panels might strengthen the hypothesis that biofilms initiate biofouling activity.

\subsection{Plankton}

From the plankton data obtained (Table 5), almost all the species of plankton from ballast water samples were also presents in the port waters and Terengganu coastal waters. The survivability of plankton in ballast tank depends on the ability of the species to adapt to the ballast tank conditions. Carney et al. (2011) reported that some organisms could survive in dark conditions for 28 days and were able to resume their normal growth when returned to light regime. As a major exporting port, Kertih Port receives a variety of ballast water from trading vessels. With approximately $80 \%$ of the vessels from domestic ports and Southeast Asia, most organisms are likely to survive the journey because of the brevity of voyages (Lavoie et al. 1999). The reestablishment of organisms from ballast water released into Kertih Port water is highly possible not only due to the short journey but also the similarity in environmental conditions, especially salinity and temperature, among neighboring countries (Keller et al. 2011).

The plankton densities in port waters were higher compared to Terengganu coastal water and ballast water with the highest number recorded during monsoon season (August 2012). Zaleha et al. (2006) revealed that densities of zooplankton were higher in near shore compared to offshore waters along the east coast of peninsular Malaysia. Higher plankton density at near shore could be attributed to adequate nutrient runoff from land (Boonyapiwat 1999; Pennington 2006). In this study, phytoplankton in all samples were dominated by diatoms. Diatoms (Coscinodiscophyceae and Bacillariophyceae) were the most abundant and widespread phytoplankton, which occur in nearly all aquatic environments (Davis 1955; Nybakken 1993). Previous studies from Terengganu near shore waters (Shamsudin et al. 1999) and coastal waters of Bachok and Kelantan (Salleh and Ruslan 2010) have reported similar findings. Additionally, Trichodesmium sp., a cyanobacterium was the dominant species in Terengganu offshore samples and its highest densities were recorded at stations 12 and 16 which accounted for more than $70 \%$ in total abundance.
Previous studies have shown that copepod nauplii were always abundant and very productive in marine waters (Humes 1994). Shamsudin et al. (1999) reported high concentrations of copepod nauplii $(720,000-980,000$ organisms $\mathrm{m}^{-3}$ ) from Terengganu and Johor waters. Shansudin et al. (1997) reported the dominance of Oithona sp. and Paracalanus sp. in South China Sea off Bachok and Kelantan. Zaleha et al. (2006) reported the dominance of calanoid and harpacticoid copepods in Terengganu waters.

\section{CONCLUSIONS}

The present study on Kertih Port biological data and physico-chemical parameters provides comprehensive information on water quality in the Port region, as well as the distribution, abundance and habitats of locally available species. As a port that always receives an admixture of water from other countries, the probability of importing alien species is high. Therefore, continuous monitoring is important to facilitate port risk management to enable timely detection of any changes in plankton community structure.

\section{ACKNOWLEDGEMENTS}

We are grateful to the ASEAN-India Cooperation project for sponsoring the biofouling study. We are indebted to the Ministry of Higher Education, Malaysia for funding the other parts of the project (59162). Special thanks are due to Marine Department Malaysia (Kertih) for assisting our team to conduct sampling on board ships and biofouling studies. We are also highly indebted to Kertih Port Sdn. Bhd. for their cooperation in providing information of ships calling at Kertih Port and for granting access to the port for biofouling studies. We gratefully acknowledge the support of ship captains for allowing us to obtain ballast water samples. We wish to thank Dr. Mohd. Fadzil Mohd. Akhir, who led the oceanography cruise that collected coastal water samples off the coast of Terengganu.

\section{REFERENCES}

[APHA] American Public Health Association. 2005. Standard methods for the examination of water and wastewater. 21 ${ }^{\text {st }}$ Edition. Washington DC: American Water Works Association, Water Environment Federation.

Beloin C, Roux A, Ghigo JM. 2008. Escherichia coli biofilms. Current Topics in Microbiology and Immunology 322:249-289.

Boonyapiwat S. 1999. Distribution, abundance and species composition of phytoplankton in South China Sea, Area 1: Gulf of Thailand and East Coast of Peninsular Malaysia. In: Proceedings of the First Technical Seminar on Marine Fishery Resources Survey in the South China Sea AREA I: Gulf of Thailand and East Coast of Peninsular Malaysia; 1997 Nov 24-26; Bangkok, Thailand. Bangkok: Southeast Asian Fisheries Development Center. p. 111-134.

Carney KJ, Delanya JE, Sawant S, Mesbahi E. 2011. The effects of prolonged darkness on temperate and tropical marine phytoplankton, and their implications for ballast water risk management. Marine Pollution Bulletin 62(6):1233-1244.

Caron DA. 1994. Inorganic nutrients, bacteria, and the microbial loop. Microbial Ecology 28:295-298. 
Chandran A, Hatha AAM. 2003. Survival of Escherichia coli in a tropical estuary. The South Pacific Journal of Natural Science 21:41-46.

David M, Perkovi M. 2004. Ballast water sampling as a critical component of biological invasions risk management. Marine Pollution Bulletin 49:313-318.

Davis CC. 1955. The marine and fresh-water plankton. Michigan: Michigan State University Press.

Department of Environment (DOE) Malaysia. 2016. Environmental quality report. Kuala Lumpur: Department of Environment Malaysia.

Desai DV, Narale D, Khandeparker L, Anil AC. 2017. Potential ballast water transfer of organisms from the west to the east coast of India: Insights through on board sampling. Journal of Sea Research 133:88-99.

Endresen $\varnothing$, Behrens HL, Brynestad S, Andersen AB, Skjong R. 2004. Challenge in global ballast water management. Marine Pollution Bulletin 48(7-8):615-623.

Green MB, Finlay JC. 2010. Patterns of hydrologic control over total nitrogen to total phosphorus ratios. Biogeochemistry 99:15-30.

Humes AG. 1994. How many copepods? In: Ferrari FD, Bradley BP, editors. Ecology and morphology of copepods. Developments in Hydrobiology 102, Hydrobiologia 292/293:1-7.

Keller PR, Drake JM, Drew MB, Lodge DM. 2011. Linking environmental conditions and ship movements to estimate invasive species transport across the global shipping network. Diversity and Distributions 17:93-102.

Khandeparker L, Anil AC, Naik SD, Gaonkar CC. 2015. Daily variations in pathogenic bacterial populations in a monsoon influenced tropical environment. Marine Pollution Bulletin 96:337-343.

Kohler KE, Gill SM. 2006. Coral Point Count with Excel extensions (CPCe): a Visual Basic program for the determination of coral and substrate coverage using random point count methodology. Computers and Geosciences 32(9):1259-1269.

Kristensen JB, Meyer RL, Laursen BS, Shipovskov S, Besenbacher F, Poulsen CH. 2008. Antifouling enzymes and the biochemistry of marine settlement. Biotechnology Advances 26:471-481.

Lavoie DM, Smitha LD, Ruiz GM. 1999. The potential for intracoastal transfer of non-indigenous species in the ballast water of ships. Estuarine, Coastal and Shelf Science 48:551-564.

Lim SC, De Voogd NJ, Tan KS. 2009. Fouling sponges (Porifera) on navigation buoys from Singapore waters. The Raffles Bulletin of Zoology 22:41-58.

Looi LJ, Aris AZ, Johari WLW, Yusoff FM, Hashim Z. 2013. Baseline metals pollution profile of tropical estuaries and coastal waters of the Straits of Malacca. Marine Pollution Bulletin 74(1):471-476.

Magnusson B, Westerlund S. 1981. Solvent extraction procedures combined with back extraction for trace metal determination by atomic absorption spectrometry. Analytica Chimica Acta 131:63-72.

McGee S, Piorkowski R, Ruiz G. 2006. Analysis of recent vessel arrivals and ballast water discharge in Alaska: toward assessing ship-mediated invasion risk. Marine Pollution Bulletin 52:1634-1645.

Nagvenkar GS, Ramaiah N. 2009. Abundance of sewagepollution indicator and human pathogenic bacteria in a tropical estuarine complex. Environmental Monitoring and Assessment 155:245-256.

Nishiguchi MK, Jones BW. 2005. Microbial biodiversity within the Vibrionaceae. Cellular Origin, Life in Extreme Habitats and Astrobiology 6:533-548.

Nybakken JW. 1993. Marine biology: an ecological approach. $3^{\text {rd }}$ edition. New York: HarperCollins.

Occhipinti-Ambrogi A, Savini D. 2003. Biological invasions as a component of global change in stressed marine ecosystems. Marine Pollution Bulletin 46:542-551.

Parsons TR, Maita Y, Lalli CM. 1984. A manual of chemical and biological methods for seawater analysis. Oxford: Pergamon Press.

Pennington JT, Mahoney KL, Kuwahara VS, Kolber DD, Calienes R, Chavez FP. 2006. Primary production in the eastern tropical Pacific: a review. Progress in Oceanography 69:285-317.

Pielou EC. 1966. The measurement of diversity in different types of biological collections. Journal of Theoretical Biology 13:131-144.

Praveena SM, Aris AZ. 2012. A baseline study of tropical coastal water quality in Port Dickson, Straits of Malacca, Malaysia. Marine Pollution Bulletin 67(1-2):196-199.

Ramaiah N, Kolhe V, Sadhasivan A. 2005. Quantitative analyses of pollution-indicator and pathogenic bacteria in Mumbai waters from ballast water exchange perspective. Environmental Monitoring and Assessment 104:295-308.

Richardson AJ, Bakun A, Hays GC, Gibbons MJ. 2009. The jellyfish joyride: causes, consequences and management responses to a more gelatinous future. Trends in Ecology and Evolution 24(6):312-322.

Roberts BJ, Howarth RW. 2006. Nutrient and light availability regulate the relative contribution of autotrophs and heterotrophs to respiration in freshwater pelagic ecosystems. Limnology and Oceanography 51(1):288-298.

Salleh A, Ruslan ND. 2010. Phytoplankton composition and distribution in the coastal area of Bachok, Kelantan. Malaysian Journal of Science 29:19-29.

Sanford E, Bermudez D, Bertness MD, Gaines SD. 1994. Flow, food supply and acorn barnacle population dynamics. Marine Ecology Progress Series 104:49-62.

Shamsudin L, Yasin AH, Razak SA, Yusoff MS. 1999. Microplankton (including dinoflagellate and foraminifera) in the South China Sea, Area 1: Gulf of Thailand and Peninsular Malaysia. In: Proceedings of the First Technical Seminar on Marine Fishery Resources Survey in the South China Sea AREA I: Gulf of Thailand and East Coast of Peninsular Malaysia; 1997 Nov 24-26; Bangkok, Thailand. Bangkok: Southeast Asian Fisheries Development Center. p. 310-335.

Shamsudin L, Yusof M, Azis A, Shukri Y. 1997. The potential of certain indigenous copepod species as live food for commercial fish larval rearing. Aquaculture 151:351-356.

Shannon CE, Weaver W. 1963. The mathematical theory of communication. Urbana: University of Illinois Press.

Suratman S, Hang HC, Shazili NAM. 2009. A preliminary study of the distribution of selected trace metals in the Besut River Basin, Terengganu, Malaysia. Bulletin of Environmental Contamination and Toxicology 82:16-19.

Suzumura M, Ingall ED. 2004. Distribution and dynamics of various forms of phosphorus in seawater: insights from field observations in the Pacific Ocean and a laboratory experiment. Deep-Sea Research 51:1113-1130.

Thompson FL, Thompson CC, Hoste B, Vandemeulebroecke 
K, Gullian M, Swings J. 2003. Vibrio fortis sp. nov. and Vibrio hepatarius sp. nov., isolated from aquatic animals and the marine environment. International Journal of Systematic and Evolutionary Microbiology 53:1495-1501.

United Nations Environment Programme (UNEP). 1992. Determination of petroleum hydrocarbons in sediments. Reference Methods for Marine Pollution Studies No. 20.

United States Environmental Protection Agency (EPA). 1986. Ambient water quality criteria for bacteria EPA/440/5-84-002. Washington DC: US Environmental Protection Agency, Office of Water, Regulations and Standards, Criteria and Standards Division.

Williams RJ, Griffiths FB, Van der Wal EJ, Kelly J. 1988. Cargo vessel ballast water as a vector for the transport of non-indigenous marine species. Estuarine, Coastal and Shelf Science 26:409-420.

Wong HC, Liu SH, Wang TK, Lee CL, Chiou CS, Liu DP, Lee B. 2000. Characteristics of Vibrio parahaemolyticus O3:K6 from Asia. Applied and Environmental Microbiology 66:3981-3986.

Yan T, Yan WX, Dong Y, Wang HJ, Yan Y, Liang GH. 2009. Marine fouling on floating installations west of Dongsha Islands, the northern South China Sea. International Biodeterioration \& Biodegradation 63(8):1079-1087.

Yildiz FH, Visick KL. 2009. Vibrio biofilms: so much the same yet so different. Trends in Microbiology 17:109-118.

Zaleha K, Sathiya BM, Iwasaki N. 2006. Zooplankton in east coast of Peninsular Malaysia. Journal of Sustainability Science and Management 1(2):87-96. 